\title{
Éditorial. Numéro confiné, pensées déconfinées
}

\section{Annabel Vallard et Gil Bartholeyns}

\section{OpenEdition}

Journals

Édition électronique

URL : https://journals.openedition.org/tc/15313

DOI : $10.4000 /$ tc. 15313

ISSN : 1952-420X

\section{Éditeur}

Éditions de l'EHESS

\section{Édition imprimée}

Date de publication : 12 mai 2021

Pagination : 6-9

ISBN : 978-2-7132-2874-2

ISSN : 0248-6016

Référence électronique

Annabel Vallard et Gil Bartholeyns, "Éditorial. Numéro confiné, pensées déconfinées », Techniques \& Culture [En ligne], 75 | 2021, mis en ligne le 12 mai 2021, consulté le 29 septembre 2022. URL : http:// journals.openedition.org/tc/15313; DOI : https://doi.org/10.4000/tc.15313 


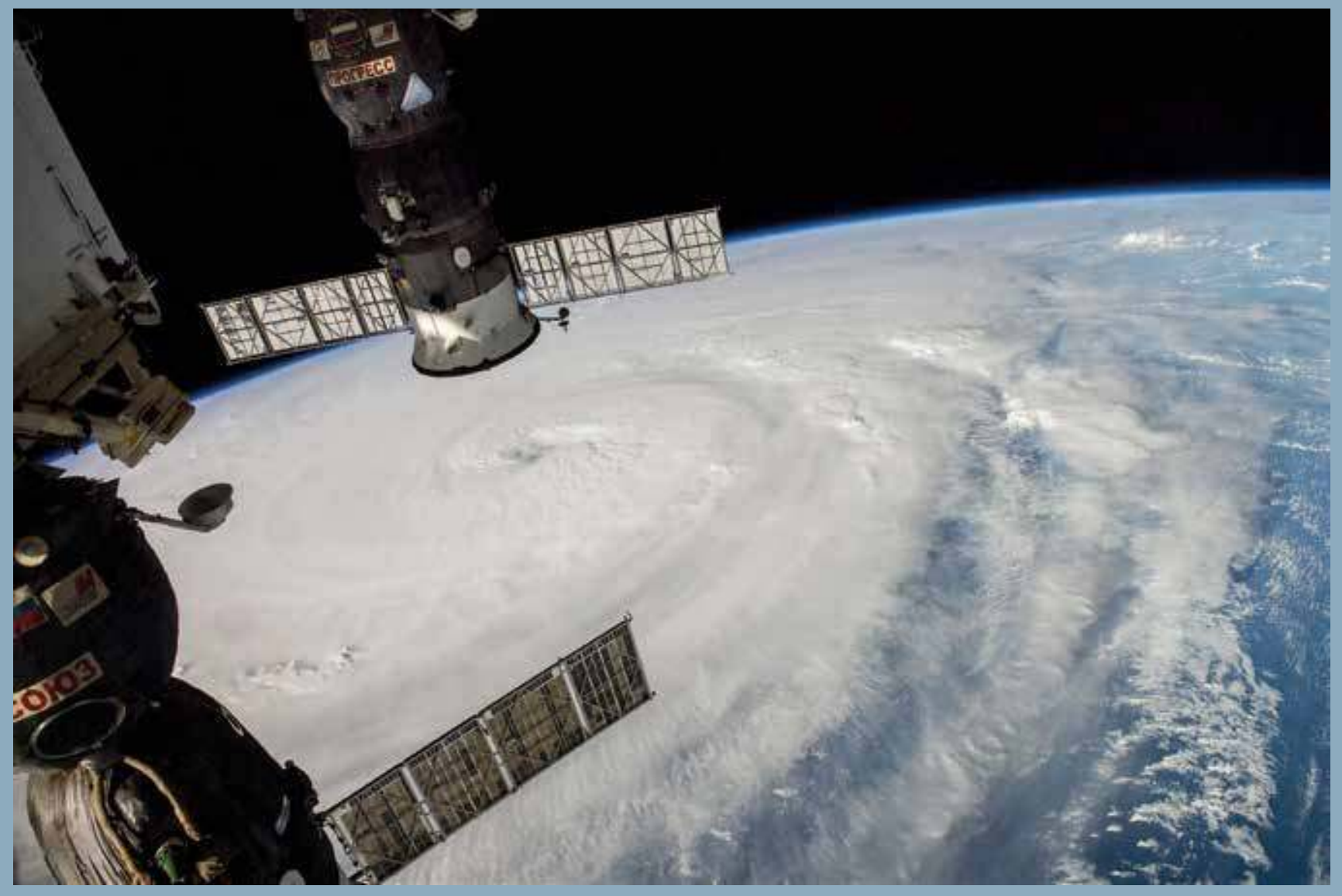




\section{Numéro confiné, pensées déconfinées}

Quand Techniques\& Culture a lancé l'appel à contributions de ce numéro ${ }^{1}$, la revue ne pensait pas que le confinement du monde était si proche, que chacun d'entre nous, à l'échelle planétaire, expérimenterait aussi radicalement la mise à l'arrêt d'activités auparavant banales et quotidiennes, l'étroitesse des murs de nos foyers, l'isolement affectif souvent, la violence d'un mouvement vital brutalement stoppé et la liberté pour certains de prendre le temps, de rêver, de s'essayer à d'autres possibles. Ce numéro s'est construit dans ce moment singulier - voué sans aucun doute à se reproduire-, à distance. De celle qui paradoxalement rapproche parfois les gens. Il en porte les traces dans ses formulations, dans son vocabulaire, dans ses noirceurs et, ici et là, dans ses désirs poétiques et ludiques.

La revue, quant à elle, a tenu la barre, en proposant un numéro de lutte («Semer le trouble ») qui a connu un succès de librairie et une réimpression inédite, les appels à l'action collective et à l'engagement aujourd'hui entravés par la situation sanitaire se concrétisant peut-être dans un autre désir, de lecture cette fois. Les membres de son comité se sont aussi essayés à déconfiner les collaborations, dans les projets de numéro à venir bien sûr -sur les savoir-faire du point de vue du Japon, sur le genre des techniques, sur le rituel - et vers des horizons éditoriaux élargis.

En partenariat avec une jeune maison d'édition d'essais et de sciences humaines grand public, Premier Parallèle, la revue prend la direction de «La vie des choses », une série de textes inédits au sein des "Carnets Parallèles», une collection ouverte et vivante qui accueille des essais courts, à cheval sur les idées et les pratiques. Ces livres partent du concret, et cheminent avec le lecteur vers le monde des idées. Nous y promouvrons ces terrains qu'arpente la revue depuis sa fondation, ces mille manières de penser autrement le monde matériel, en commençant, dès septembre prochain par L'étrange et folle aventure du grille-pain, de la machine à coudre et de ceux qui s'en servent (Gil Bartholeyns \& Manuel Charpy) 
et Le mythe du recyclage (Mikaëla Le Meur). Élargissant son aventure éditoriale collective, la revue continue ainsi à affirmer que la connaissance ne doit pas seulement se rencontrer dans les bibliothèques universitaires, mais passer de main en main, pour redonner toute sa richesse au mot «publication».

À l'heure de finaliser ce numéro, et tandis que Thomas Pesquet, cet astronaute français bien aimé des médias et du public, tourne en orbite basse pour la seconde fois de son existence autour de la Terre, dans ce confinement choisi de la station spatiale internationale, nous avons une pensée pour Georges Guille-Escuret, un ami de la revue parti discrètement rejoindre les étoiles. Personne ne dissertait comme lui, avec un aplomb redoutable, sur les termites, le cannibalisme et le marxisme. Nous pensons aujourd'hui à son immense générosité, à son rire gargantuesque, à ses irrévérences, à ses cigares, aux vins du Languedoc, à sa discrétion, à son départ radical et lui dédions ce numéro. Le temps de l'hommage viendra.

1. Couvertures des premiers titres à paraître en septembre dans la série «La vie des choses», placée sous la direction de TechniquesotCulture: aux éditions Premier Parallèle

\section{GIL BARTHOLEYNS MANUEL CHARPYY}

L'ETRANGE ET FOLLE AVEN TURE DUGRLLEPAS DE LA MACTIINE A GOUDRE LT DES GENS GUI S'EN GERVEMT

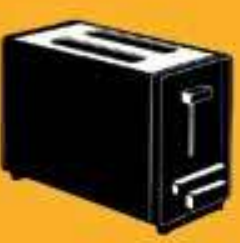

P'

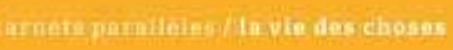

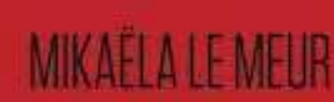

LEMYTHE DU RECYCLAGE

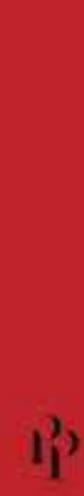




\section{Notes}

1. Nos remerciements à Stéphane Rennesson, co-éditeur scientifique du numéro, pour ces «pensées déconfinées », formule qui nous a accompagnés dans nos échanges avec les auteurs au fil du premier confinement.

\section{Iconographie}

Image d'ouverture. L'un des membres de l'équipage Expedition 40 à bord de la Station spatiale internationale a photographié cette image du super typhon Neoguri se dirigeant vers le Japon à 21:56:56 GMT le 5 juillet 2014. Un véhicule russe Soyouz, amarré à l'avant-poste

orbital, est partiellement visible au premier plan, et un Progress russe amarré est visible en haut à gauche. (c) Reid Wiseman.

1. C Premier Parallèle.

\section{Pour citer l'article}

Vallard, A. \& G. Bartholeyns 2021 «Éditorial. Numéro confiné, pensées déconfinées», TechniquesECulture 75 «Abîmes, abysses, exo-mondes. Explorations en milieux-limites», p. 6-9. 